\title{
Assessment of linezolid efficacy, safety and tolerability in the treatment of tuberculosis: $A$ retrospective case review
}

\author{
Alena Tse-Chang MD¹, Dennis Kunimoto MD², Evelina Der BScN RN³ , Rabia Ahmed MD²
}

\begin{abstract}
A Tse-Chang, D Kunimoto, E Der, R Ahmed. Assessment of linezolid efficacy, safety and tolerability in the treatment of tuberculosis: A retrospective case review. Can J Infect Dis Med Microbiol 2013;24(3):e50-e52.

Linezolid is a potentially effective drug for the treatment of patients with drug-resistant tuberculosis. Among 13 patients treated for tuberculosis with linezolid in the present study, nine had treatment success and four remain on treatment. Adverse effects occurred in 11 (85\%) patients, of whom three discontinued treatment because of adverse effects. The present study adds to the growing evidence supporting the efficacy of linezolid for tuberculosis, although treatment remains complicated by adverse effects.
\end{abstract}

Key Words: Drug-resistant TB; Linezolid; Toxicity; Treatment outcomes

\author{
L'évaluation de l'efficacité, de l'innocuité et de la \\ tolérabilité du linézolide dans le traitement de la \\ tuberculose : une analyse rétrospective de cas
}

Le linézolide est un médicament qui peut être efficace dans le traitement de patients atteints d'une tuberculose résistant aux médicaments. Dans la présente étude, chez 13 patients traités au linézolide contre la tuberculose, neuf ont vu leur traitement réussir et quatre sont toujours en traitement. Des effets indésirables se sont manifestés chez 11 (85\%) patients, dont trois ont arrêté le traitement pour cette raison. La présente étude s'ajoute aux données croissantes étayant l'efficacité du linézolide pour soigner la tuberculose, même si le traitement demeure compliqué par des effets indésirables.

he treatment of tuberculosis (TB) becomes more complicated as the antibiotic resistance profile of Mycobacterium tuberculosis increases, especially in the case of multidrug-resistant (MDR) and extensively drug-resistant (XDR) TB. Treatment then depends largely on anti-TB agents that may be less potent or not well tolerated. Thus, information regarding efficacy, safety and tolerability of other antibiotics that are potentially useful in treatment is important to improve outcomes in drug-resistant TB (DR-TB).

In vitro and pharmacological data suggest that linezolid, an oxazolidinone antibiotic, may be useful in the treatment of TB. Varied reports regarding linezolid's safety and tolerability, mostly due to the occurrence of dose- and duration-dependent reversible myelosuppression and peripheral and optic neuropathy, have been documented in the literature. Despite these toxicities, cures have been reported among patients with MDR/XDR-TB treated with a linezolid regimen. The present study aimed to describe outcomes in a case series of TB patients treated with a linezolid-containing regimen.

\section{METHODS}

All cases of active, culture-confirmed M tuberculosis infection treated with a linezolid-containing regimen in the northern Canadian city of Edmonton, Alberta, as well as the rural communities of the province between January 1, 2000 through December 31, 2011 were reviewed. Demographic and clinical data were extracted through retrospective chart review and from the Integrated Public Health Information System for TB. Data review was censured on April 30, 2012.

Treatment outcome of linezolid-containing regimens was defined by clinical, radiographic, and smear and culture results as applicable. For pulmonary cases, treatment success was defined by culture conversion, treatment completion and a negative end-of-follow-up sputum culture. For extrapulmonary cases, treatment success was defined by treatment completion with no clinical or radiographic signs of activity at the end of follow-up. Relapse was defined as recurrence of positive cultures requiring retreatment after apparent treatment success. Time to culture conversion was defined as time from treatment start to the date of the first of two consecutive negative cultures.
The safety and tolerability of linezolid were assessed by reviewing monthly complete blood count data and inquiries regarding neuropathy. The treating physician determined whether myelosuppression, peripheral neuropathy or optic neuropathy were attributable to linezolid. Anemia was defined as a hemoglobin level $<135 \mathrm{~g} / \mathrm{L}$ or a progressive drop in hemoglobin; leukopenia was defined as a white blood cell count $<4.0 \times 10^{9} / \mathrm{L}$; and thrombocytopenia was defined as a platelet count $<140 \times 10^{9} / \mathrm{L}$.

\section{RESULTS}

Between January 1, 2000 and December 31, 2011, 13 patients (seven female, six male) with a mean age of 38 years (range 15 to 72 years) with culture-confirmed TB were treated with linezolid as part of their multidrug regimens (Table 1). All patients were foreign-born and one had HIV coinfection.

Of the 13 patients, one had a history of previous treatment for TB. Five $(38 \%)$ patients had pulmonary disease, four (31\%) had lymph node disease and one (8\%) had spinal disease. Three patients $(23 \%)$ had pulmonary TB and one other site of disease (Table 1). Of the eight patients with pulmonary $\mathrm{TB}$, one (13\%) exhibited cavitary changes on initial chest radiograph or computed tomography and six (75\%) had positive sputum smear microscopy results at the time of diagnosis. Drug susceptibility test results are summarized in Table 1. Six patients had MDR-TB. The median number of drugs to which $\mathrm{M}$ tuberculosis isolates were resistant was five (range zero to seven drugs).

Indications for using linezolid were failure of previous treatment regimens $(n=1)$, presence of extensive drug resistance $(n=9)$ or inability to tolerate other drugs $(n=3)$. One patient (patient 13) had pulmonary TB with a fully susceptible $M$ tuberculosis isolate, but developed vertebral TB while in the continuation phase of treatment. Linezolid was thus added to intensify treatment. Patients had been on other drugs for TB for a median of 1.5 months (range zero to 12 months) before starting linezolid (Table 1). The dose of linezolid was always $600 \mathrm{mg}$ once daily. The dose of vitamin $\mathrm{B}_{6}$ was $25 \mathrm{mg}$ to $100 \mathrm{mg}$ daily. The median number of TB medications used concurrently was three (range one to four [Table 1]). The mean duration of linezolid administration was 8.3 months (range 1.4 to 22 months).

${ }^{1}$ Department of Pediatrics; ${ }^{2}$ Department of Medicine, University of Alberta $;{ }^{3}$ Central TB Services, Alberta Health Services, Edmonton, Alberta Correspondence: Dr Alena Tse-Chang, Room 9232, Aberhart Centre One, 11402 University Avenue, Edmonton, Alberta T6G 2J3.

Telephone 780-407-4550, fax 780-407-4562, e-mail alena.tse2@albertahealthservices.ca 


\begin{tabular}{|c|c|c|c|c|c|c|c|c|c|c|c|}
\hline Patient & $\begin{array}{l}\text { Sex, age at } \\
\text { treatment } \\
\text { initiation, } \\
\text { years }\end{array}$ & $\begin{array}{l}\text { Country } \\
\text { of birth }\end{array}$ & $\begin{array}{l}\text { Disease } \\
\text { site }\end{array}$ & $\begin{array}{l}\text { Comorbid } \\
\text { conditions }\end{array}$ & $\begin{array}{l}\text { Disease at } \\
\text { time of } \\
\text { diagnosis }\end{array}$ & $\begin{array}{l}\text { Smear } \\
\text { result at } \\
\text { time of } \\
\text { diagnosis }\end{array}$ & $\begin{array}{l}\text { Resistance } \\
\text { pattern }\end{array}$ & $\begin{array}{c}\text { Duration } \\
\text { on TB } \\
\text { drugs } \\
\text { before } \\
\text { LZD, } \\
\text { months }\end{array}$ & $\begin{array}{l}\text { Concurrent } \\
\text { medications } \\
\text { to LZD }\end{array}$ & $\begin{array}{l}\text { Total } \\
\text { months on } \\
\text { LZD* }\end{array}$ & $\begin{array}{c}\text { Total } \\
\text { duration of } \\
\text { TB } \\
\text { treatment, } \\
\text { months }\end{array}$ \\
\hline 1 & $F, 15$ & Philippines & Pulmonary & None & Noncavitary & Positive & INH, PZA, EMB & 0.75 & RIF, MFX & 11.5 & 12 \\
\hline 2 & $M, 42$ & Vietnam & $\begin{array}{l}\text { Pulmonary, } \\
\text { lymph } \\
\text { node }\end{array}$ & $\begin{array}{l}\text { Alcohol } \\
\text { abuse }\end{array}$ & Noncavitary & Positive & $\begin{array}{l}\text { INH, RIF, PZA, } \\
\text { STM, low-level } \\
\text { RIB }\end{array}$ & 1 & $\begin{array}{l}\text { MFX, AMK, } \\
\text { EMB, ETA }\end{array}$ & 9.7 & Ongoing \\
\hline 3 & M, 37 & Vietnam & $\begin{array}{l}\text { Pulmonary, } \\
\text { pleural }\end{array}$ & None & Noncavitary & Negative & $\begin{array}{l}\text { INH, RIF, PZA; } \\
\text { low-level EMB and } \\
\text { STM }\end{array}$ & 1 & $\begin{array}{l}\text { MFX, AMK, } \\
\text { EMB (high } \\
\text { dose) }\end{array}$ & 10 & 11 \\
\hline 4 & $F, 28$ & India & Pulmonary & None & Cavitary & Negative & $\begin{array}{l}\text { INH, RIF, PZA, } \\
\text { STM, RIB, OFX, } \\
\text { ETA } \\
\text { (microcolonies) }\end{array}$ & 0 & $\begin{array}{l}\text { PAS, AMK, } \\
\text { EMB }\end{array}$ & $\begin{array}{l}\text { Ongoing } \\
\text { (10) }\end{array}$ & Ongoing \\
\hline 6 & M, 35 & Ethiopia & $\begin{array}{r}\text { Lymph } \\
\text { node }\end{array}$ & Travel & N/A & Negative & $\begin{array}{l}\text { INH, RIF, PZA, } \\
\text { EMB, STM, ETA, } \\
\text { RIB }\end{array}$ & 1 & AMK, LFX & 10.2 & 12 \\
\hline 7 & $\mathrm{M}, 70$ & China & Pulmonary & None & Noncavitary & Positive & None & 3 & AMK, EMB & 1.4 & 12 \\
\hline 8 & $F, 31$ & Cambodia & $\begin{array}{l}\text { Lymph } \\
\text { node }\end{array}$ & None & N/A & Positive & $\begin{array}{l}\text { INH, RIF, EMB, } \\
\text { STM, RIB }\end{array}$ & 1.5 & $\begin{array}{r}\text { MFX, AMK, } \\
\text { PAS, PZA }\end{array}$ & 5.5 & 12 \\
\hline 9 & $F, 41$ & Indonesia & Lymph node & HIV positive & N/A & Negative & $\mathrm{INH}$ & 7 & $\mathrm{RIB}$ & 1.4 & 12 \\
\hline 10 & $F, 72$ & China & Pulmonary & Asthma & Noncavitary & Positive & OFX, STM & 6 & INH, EMB & 6.4 & 12 \\
\hline 11 & $F, 34$ & Philippines & $\begin{array}{l}\text { Lymph } \\
\text { node }\end{array}$ & None & N/A & Negative & $\begin{array}{l}\text { INH, RIF, PZA, } \\
\text { STM, ETA }\end{array}$ & 4 & $\begin{array}{l}\text { MFX, AMK, } \\
\text { RIB (EMB } \\
\text { for } 19 \\
\text { days) }\end{array}$ & $\begin{array}{l}\text { Ongoing } \\
(3.6)\end{array}$ & Ongoing \\
\hline
\end{tabular}

*'Ongoing' indicates that the patient was still receiving linezolid ( $L Z D)$ treatment at data censure, number in parentheses indicates number of months of $L Z D$ treatment to date. AMK Amikacin; AZM Azithromycin; EMB Ethambutol; ETA Ethionamide; F Female; INH Isoniazid; M Male; MFX Moxifloxacin; N/A Not applicable; OFX Ofloxacin; PAS Para-aminosalicylic acid; PZA Pyrazinamide; RIB Rifabutin; RIF Rifampin; STM Streptomycin; TB Tuberculosis

At data censure, nine (69\%) of 13 patients had successfully completed treatment (Table 2) including three patients with MDR-TB. Four patients (31\%) were still receiving treatment. Among the eight patients with pulmonary disease, all achieved culture conversion by the time of data censure: five $(62 \%)$ did so before starting linezolid, while three (38\%) did so after starting linezolid (range one to nine weeks). To date, there have been no deaths or unsatisfactory outcomes.

Of the 13 patients, 11 (85\%) experienced adverse events attributed to linezolid (Table 2), with all 11 experiencing hematological sides effects. Adverse events resulted in discontinuation of linezolid therapy in three patients (for anemia, peripheral neuropathy and rash) and interruption of linezolid therapy in one patient (for gastrointestinal side effects).

\section{DISCUSSION}

Treatment outcomes for DR-TB are typically worse because of the lack of potent bactericidal drugs, the duration of treatment, and the side effects and toxicities of second-line medications. Linezolid has been shown to be effective in the treatment of DR-TB in several case series (1-12). A meta-analysis and systematic review of 11 studies $(n=148$ patients), in which linezolid was used in the treatment of DR-TB, demonstrated a pooled proportion of treatment success of $68 \%$ (13). This is comparable with outcomes for MDR-TB treatment in general, with a reported pooled proportion of $62 \%$ treatment success $(13,14)$. A second meta-analysis and systematic review of 12 studies in which linezolid was used in the treatment of MDR-TB (15) found $86(92.5 \%)$ of 93 cases achieved a negative smear and 100 (93.5\%) of 107 achieved culture conversion after treatment with individualized regimens containing linezolid. The efficacy of linezold in the treatment of DR-TB was further demonstrated in the treatment of refractory XDR-TB with the addition of linezolid, resulting in culture conversion within six months (16). In our study, all patients who completed treatment achieved cure and three (38\%) of these achieved culture conversion while on linezolid. Furthermore, three of six patients with confirmed MDR-TB achieved cure while the remainder were on treatment at data censure. However, because all patients in our series were receiving multidrug regimens, including eight who were also receiving newer fluoroquinolones, treatment success cannot be attributed solely to the inclusion of linezolid in the regimen.

Several studies have reported toxicities, primarily myelosuppression and neuropathy, to be limiting factors in the use of linezolid. In a meta-analysis (13), the pooled estimate for the frequency of any 
TABLE 2

Treatment outcomes and toxicities

\begin{tabular}{|c|c|c|c|c|c|c|}
\hline Patient & $\begin{array}{l}\text { LZD dose, } \\
\mathrm{mg}\end{array}$ & $\begin{array}{c}\text { Vitamin } \mathrm{B}_{6} \\
\text { dose, } \mathrm{mg}\end{array}$ & $\begin{array}{l}\text { Time to culture } \\
\text { conversion on LZD } \\
\text { regimen, weeks }\end{array}$ & Reported toxicity & Reason for discontinuing LZD & Treatment outcome \\
\hline 1 & 600 & 100 & 0 & Leukopenia & Completion of therapy & Cure \\
\hline 2 & 600 & 100 & 1 & Rash, anemia & Rash & Continued treatment \\
\hline 3 & 600 & 100 & 0 & Anemia & Completion of therapy & Cure \\
\hline 4 & 600 & 100 & 9 & Anemia & Treatment current & Continued treatment \\
\hline 5 & 600 & 50 & 4 & $\begin{array}{l}\text { Leukopenia, neutropenia, } \\
\text { thrombocytopenia }\end{array}$ & Completion of therapy & Cure \\
\hline 6 & 600 & 25 & $\mathrm{~N} / \mathrm{A}$ & $\begin{array}{l}\text { Anemia, nausea, vomiting, } \\
\text { hyperpigmentation of oral cavity }\end{array}$ & $\begin{array}{l}\text { LZD interrupted and resumed; } \\
\text { completion of therapy }\end{array}$ & Cure \\
\hline 7 & 600 & 50 & 0 & Anemia & Change of recommendation & Cure \\
\hline 8 & 600 & 25 & N/A & Anemia, peripheral neuropathy & Peripheral neuropathy & Cure \\
\hline 9 & 600 & 25 & $\mathrm{~N} / \mathrm{A}$ & Anemia, leukopenia, neutropenia & Hemolysis (anemia) & Cure \\
\hline 10 & 600 & 50 & 0 & None & Completion of therapy & Cure \\
\hline 11 & 600 & 50 & $\mathrm{~N} / \mathrm{A}$ & Anemia & Treatment current & Continued treatment \\
\hline 12 & 600 & 50 & N/A & Anemia & Treatment current & Continued treatment \\
\hline 13 & 600 & 100 & 0 & None & Completion of therapy & Cure \\
\hline
\end{tabular}

LZD Linezolid; N/A Not applicable

adverse events was $61.5 \%$, with $36.2 \%$ discontinuing linezolid due to adverse events. In our small series, $85 \%$ of patients experienced adverse events, with only $23 \%$ discontinuing because of toxicity. Pooled proportions of the frequency of neuropathy and bone marrow suppression in previous studies were $36.1 \%$ and $28.5 \%$, respectively (13). A second meta-analysis reported adverse events in 63 (58.9\%) of 107 patients: $54(68.4 \%)$ of 79 were major adverse events including anemia $(38.1 \%)$, peripheral neuropathy $(47.1 \%)$, gastrointestinal disorders $(16.7 \%)$, optic neuritis $(13.2 \%)$ and thrombocytopenia $(11.8 \%)$ (15). In our series, hematological side effects represented the most common toxicity, with $85 \%$ having anemia. One possibility for the increased rates of bone marrow toxicity observed in our study may relate to varying sensitivities in definitions and reporting of bone marrow toxicity among studies. Although the incidence of bone marrow toxicity was increased in our study, the number of patients requiring discontinuation of linezolid was low, suggesting that the severity of toxicity was low. Other known toxicities of linezolid, including optic neuropathy, lactic acidosis and serotonin syndrome, were not apparent in our study. It has been suggested that reduced daily doses $(<600 \mathrm{mg})$ may lower the frequency of adverse events without impacting treatment success $(1,6,13,15-17)$.

Our study was limited by the small number of patients and the retrospective nature of our analysis. However, it supports growing evidence that linezolid may be efficacious in the treatment of DR-TB, although treatment is complicated by adverse events. The optimal dose remains to be determined.

ACKNOWLEDGEMENTS: The authors acknowledge the contribution of the nurses and staff at the Edmonton TB Clinic and Central TB Services. They also acknowledge Dr Anne Fanning and Dr Joan Robinson for their review of the manuscript.

\section{REFERENCES}

1. Park IN, Hong SB, Oh YM, et al. Efficacy and tolerability of daily half dose linezolid in patients with intractable multidrug resistant TB. J Antimicrob Chemother 2006;58:701-4.

2. von der Lippe B, Sandven P, Brubakk O. Efficacy and safety of linezolid in multidrug resistant TB (MDR-TB) - a report of ten cases. J Infect 2006;52:92-6.

3. Condos R, Hadgiangelis N, Leibert E, et al. Case series report of a linezolid-containing regimen for extensively drug-resistant TB. Chest 2008;134:187-92.
4. Yew WW, Chau CH, Wen KH. Linezolid in the treatment of 'difficult' multidrug-resistant tuberculosis. Int J Tuberc Lung Dis 2008;12:345-6.

5. Fortun J, Martin-Davila P, Navas E, et al. Linezolid for the treatment of multidrug-resistant tuberculosis. J Antimicrob Chemother 2005;56:180-5.

6. Nam HS, Koh WJ, Kwon OJ, Cho SN, Shim TS. Daily half-dose linezolid for the treatment of intractable multidrug-resistant tuberculosis. Int J Antimicrob Agents 2009;33:92-3.

7. Koh WJ, Kwon OJ, Gwak H, et al. Daily $300 \mathrm{mg}$ dose of linezolid for the treatment of intractable multidrug-resistant and extensively drug resistant tuberculosis. J Antimicrob Chemother 2009;64:388-91.

8. Migliori GB, Eker B, Richardson MD, et al. A retrospective TBNET assessment of linezolid safety, tolerability and efficacy in multidrug-resistant tuberculosis. Eur Respir J 2009;34:387-93.

9. Anger HA, Dworkin F, Sharma S, et al. Linezolid use for treatment of multidrug-resistant and extensively drug-resistant tuberculosis, New York City, 2000-06. J Antimicrob Chemother 2010;65:775-83.

10. Udwadia ZF, Sen T, Moharil G. Assessment of linezolid efficacy and safety in MDR- and XDR-TB: An Indian perspective. Eur Respir J 2010;35:936-8.

11. Xu HB, Jiang, RH, Li L, Xiao HP. Linezolid in the treatment of MDR-TB: A retrospectiveclinical study. Int J Tuberc Lung Dis 2012;16;358-63.

12. Singla R, Caminero JA, Jaiswal A, et al. Linezolid: An effective, safe and cheap drug for patients failing multidrug-resistant tuberculosis treatment in India. Eur Respir J 2012;39:956-62.

13. Cox H, Ford N. Linezolid for the treatment of complicated drugresistant tuberculosis: A systematic review and meta-analysis. Int J Tuberc Lung Dis 2012;16:447-54.

14. Orenstein EW, Basu S, Shah NS, et al. Treatment outcomes among patients with multidrug-resistant tuberculosis: Systematic review and meta-analysis. Lancet Infect Dis 2009;9:153-61.

15. Sotgui G, Centis R, D’Ambrosio L, et. al. Efficacy, safety, and tolerability of linezolid containing regimens in treating MDR-TB and XDR-TB: Systematic review and meta-analysis. Eur Respir J 2012;40:1430-42.

16. Lee M, Lee J, Carroll MW, et al. Linezolid for the treatment of chronic extensively drug resistant tuberculosis. N Engl J Med 2012;267:1508-18

17. Koh WJ, Kang YR, Jeon K, et al. Daily $300 \mathrm{mg}$ dose of linezolid for multidrug-resistant and extensively drug-resistant tuberculosis: Updated analysis of 51 patients. J Antimicrob Chemother 2012;67:1503-7. 


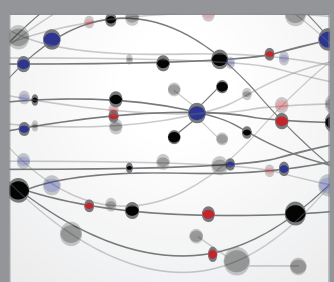

The Scientific World Journal
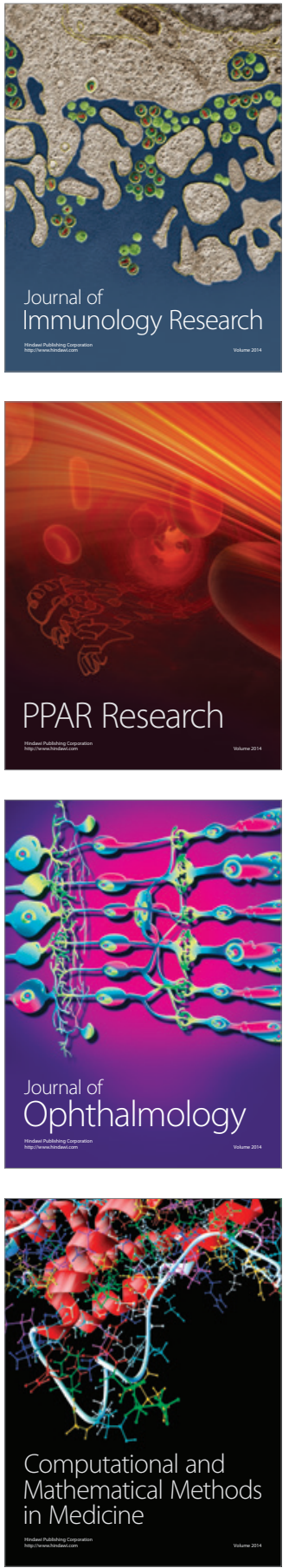

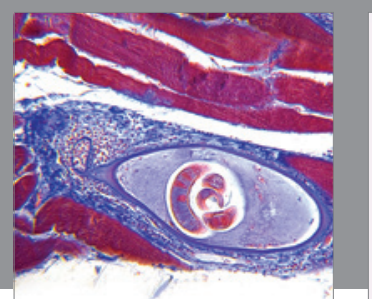

Gastroenterology Research and Practice

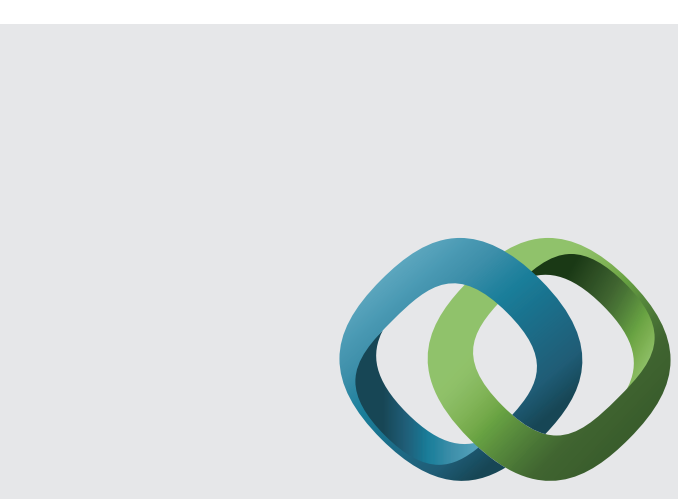

\section{Hindawi}

Submit your manuscripts at

http://www.hindawi.com
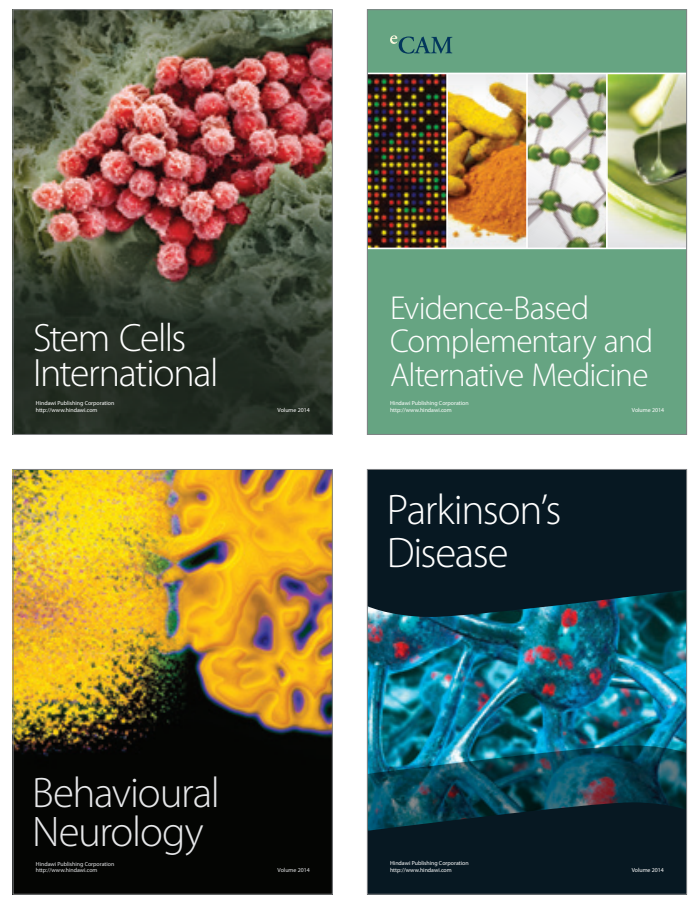
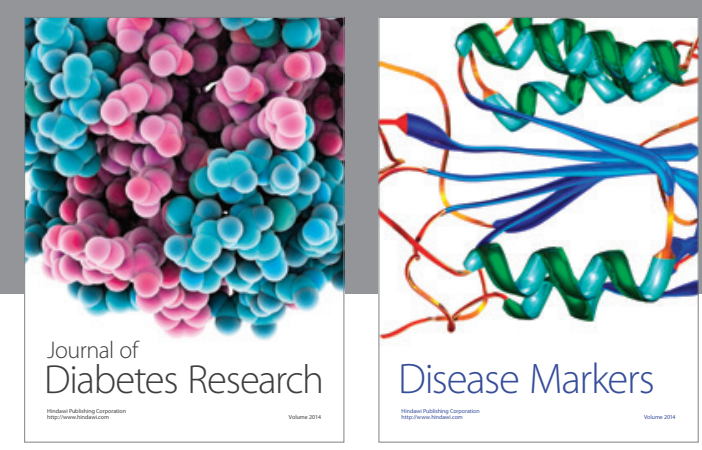

Disease Markers
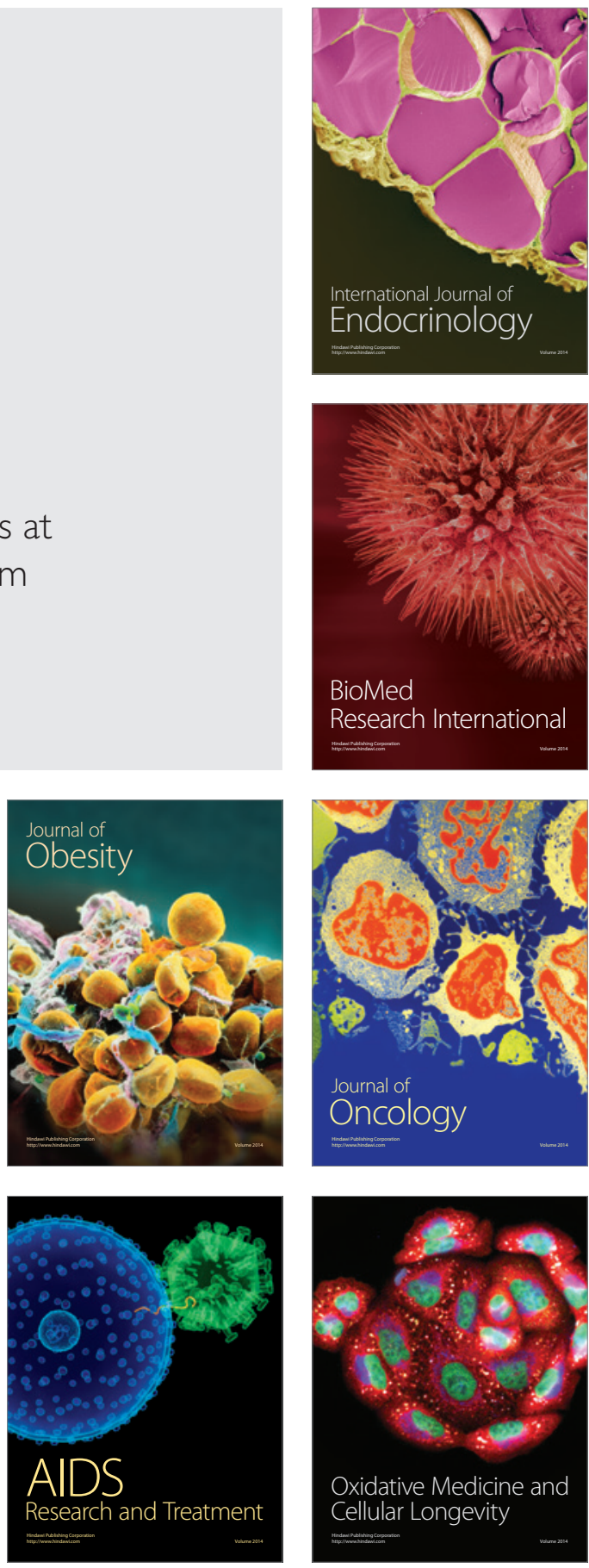